\title{
CARTOGRAFIA DINÂMICA: TEMPO E ESPAÇO NOS MAPAS
}

\author{
Marcello Martinelli*
}

\section{RESUMO:}

A abordagem da realidade espacial por mapa não pode ignorar a dimensão temporal, pois a representação do espaço social considerará uma vida no tempo, no presente e no passado. A dinâmica da sociedade altera-se no tempo, imprimindo mudanças no espaço. Assim, a representação do espaço registrará combinadamente, marcas do passado e transformações do presente. Minard estabeleceu as bases para as representações dinâmicas em 1840. Ele inventou os Mapas de fluxos. No presente, a revolução tecnológica colocou a cartografia dinâmica em correspondência com a manipulação interativa da informação espacial. Com esta inovação surgem dois novos modos de expressão: a interação e a animação, que confirmarão uma cartografia mais consistente.

\section{PALAVRAS-CHAVE:}

Cartografia dinâmica, visualização cartográfica, mapas animados, animação interativa.

\section{ABSTRACT:}

The deal with spatial reality by map do not can ignore the temporal dimension, because the social space representation will consider a life, in the present and in the past times. The society's dynamics changes through the time imposing spatial alterations. Therefore, the space representation will register, in a combined form, past marks and present transformations. Minard conceived the bases for the dynamic representations in 1840 . He invented the Flow maps. At present time, the technological revolution sited the dynamic cartography in correspondence to the interactive manipulation of spatial information. With this innovation emerge two new modes of expression: the interaction and the animation, which will confirm a more consistent cartography.

\section{KEY WORDS:}

Dynamic cartography, cartographic visualization, animated maps, interactive animation.

\section{Introdução}

A abordagem espacial da realidade por mapa não pode desconsiderar a dimensão temporal, pois, a representação do espaço compreenderá uma vida no tempo, no presente e no passado.

A dinâmica da sociedade altera-se no tempo, imprimindo alterações no espaço. Portanto, na representação do espaço estarão registradas, combinadamente, marcas do passado e transformações que vigem no presente.

O mundo que está à nossa volta não é estático, imutável; é produto das atividades da sociedade humana, sendo, portanto, histórico. Para assimilarmos a totalidade do espaço que está no mapa, ele deverá fornecer as bases para a compreensão das transformações que se operaram nele ao longo do tempo. (DEUS, 1995)

* Professor Doutor do Departamento de Geografia da Faculdade de Filosofia, Letras e Ciências Humanas da Universidade de São Paulo. E-mail: cartotem@ig.com.br 


\section{Antecedentes}

Um primeiro mapa que representou a estrutura ou padrão do dinamismo de fatos geográficos deveu-se ao registro da circulação das águas oceânicas num planisfério, por obra de Kircher publicada em 1665, um fenômeno da natureza. A mobilidade destas decorre dos ventos. Sendo assim, podemos considerar que a circulação atmosférica teria sido objeto para a elaboração de um primeiro mapa temático, aquele realizado por Halley em 1686 para registrar os ventos alísios e as monções sobre os oceanos. Entretanto, tanto num como noutro mapa, não apareciam as indicações das direções. Estavam explicitadas no texto.

Mas foi no curso da Primeira Revolução Industrial (1750 - 1850) que, ao se consolidar uma cartografia para o estabelecimento das ferrovias, se deu, como conseqüência, o aparecimento de uma ansiedade pela busca da avaliação da circulação por estas vias. As redes de transportes constituíam um fator básico na geração de riqueza e desenvolvimento.

Estes condicionantes se inscreveram num novo contexto intelectual: o homem tornou-se objeto da ciência estimulando a possibilidade de sua representação, não só no que tange à sua distribuição no espaço, como também às suas atividades. Assistimos, assim, como resposta, aos primeiros passos na busca da expressão gráfica das quantidades demográficas.

Mas será MINARD que lançará as bases para a cartografia do dinamismo econômico da Europa. Mesmo com a presença de algumas estatísticas anteriores, foi só após 1840, com os mapas deste autor, que se confirmou uma cartografia quantitativa voltada à economia e sua dinâmica.

A cartografia de MINARD é a cartografia que vai privilegiar a marcante mobilidade dos homens e das mercadorias da Revolução Industrial, em contraste com a insipiente circulação pré-industrial.

Sem dúvida alguma seus mapas temáticos se dirigiram ao planejamento. Abordavam dinâmicas espaciais e temporais, com vistas à economia política e à geografia econômica. Eles mostravam diretamente a proporção, superando a ineficiência da representação quantitativa estática por ordem visual entre as cores.

MINARD inventou, assim, a Cartografia dos Fluxos, uma cartografia dos movimentos de circulação. Entretanto, é preciso frisar que as representações em gráficos a antecederam. Seus gráficos de 1844 e 1845 são histogramas. Em abscissas estão as distâncias entre as estações da rede ferroviária. Nas ordenadas encontra-se o número de passageiros ou toneladas de mercadoria, resultando numa série de retângulos justapostos. Estes podem ser divididos em faixas horizontais proporcionais aos componentes seletivos dos totais veiculados nos trechos considerados. Os sentidos são dados por flechas.

Em 1845 MINARD passou definitivamente do gráfico para o mapa, apresentando o Mapa da circulação de passageiros por ônibus para a porção centro-leste da França.

Seus mapas de exportação de carvão inglês para o mundo, de 1854, e do movimento de passageiros nas ferrovias da Europa, de 1862, confirmaram definitivamente esta cartografia. Sua invenção foi considerada como a primeira sistematização do emprego da variável visual tamanho para exprimir as quantidades, no caso específico aquelas que significam intensidade de movimento.

\section{As bases metodológicas}

Do ponto de vista metodológico, as representações dinâmicas constituem ainda hoje um grande desafio para a cartografia. Podemos dizer que se trata de uma busca consciente em prol da sistematização de uma cartografia dinâmica. Este desafio ganha grande ímpeto por conta não só da necessidade de representação da mutação rápida da geografia em que vivemos atualmente, mas também da cobrança por parte de um planejamento que deve subsidiar a ação em favor de setores de acelerada transformação ou de áreas sensíveis, frágeis ou instáveis da realidade. (STEINBERG e HUSSER, 1988).

Entretanto, mais recentemente, o termo cartografia dinâmica passa a referir-se 
especificamente à manipulação interativa da informação espacial, possível em tempo real, fruto dos grandes avanços tecnológicos, envolvendo a informática, a cartografia assistida por computador - a geomática -, o que certamente promoverá profundas mudanças na disciplina. (MACEACHREN e TAYLOR, 1994).

Apesar de todos estes progressos, podemos verificar que persistem ainda questões em nível metodológico.

Embora ainda presas a tais questionamentos, as representações dinâmicas deverão ocupar posição de destaque na cartografia atual, pois a realidade, hoje em dia, mais do que nunca, é essencialmente mutante, fluída, não estática, congelada, como exposto no início.

À cartografia deveria interessar mais os processos do que formas, padrões, fatos passíveis de observação imediata. As formas não trariam em si as explicações. São as aparências. Ignoraríamos, desta feita, os processos que as elaboraram. A cartografia deveria explorar e tentar resolver cada vez melhor a representação desta dinâmica, em seu total movimento.

Por outro lado, tempo e espaço são dois aspectos fundamentais da existência humana. Tudo o que existe situa-se num tempo, ocupando um espaço, bem como tudo o que acontece também tem vida num tempo e num espaço. Tudo à nossa volta está em contínua ação. Certos objetos mudam de posição no espaço com o tempo, como também se operam mudanças nas suas características: é marcante o aspecto mutante da vegetação na sucessão das quatro estações do ano, principalmente nas zonas temperadas. (MUEHRCKE, 1983).

A natureza do tempo em si pode ser vislumbrada de várias maneiras. Uma delas é o tempo físico. Este passa sem cessar a despeito da ação do homem. É o tempo natural, o das relações terrestres, estruturado pelo ritmo diário entre o claro e o escuro, o ciclo mensal da lua, a sucessão anual das estações. Já em 3.500 a.C. o homem anotava a passagem do dia e da noite com um relógio solar. É a noção cíclica do tempo. (ANTUNES et al.,1993).
O tempo biológico, por sua vez, é o tempo de todos os seres vivos, evidentemente relacionados com o ritmo da Terra, sol, estrelas, segundo um delicado e preciso relógio biológico. Qualquer descontrole nesta contagem pode causar stress haja vista o caso de uma viagem rápida atravessando muitos fusos horários, tanto para leste como para oeste. O transcorrer deste tempo também não é constante: a latitude, altitude e condições climáticas condicionam o seu andamento. Como componente naturalmente ordenado, o tempo pôde, assim, se tornar quantitativo somente a partir do momento em que a humanidade reconheceu no dia, no ano, e, numa época relativamente recente, mediante o segundo atômico, a presença de unidades intervalares suficientemente estáveis. Assim, por comodidade, a sociedade adotou como referencial básico o tempo do relógio e do calendário. (BERTIN, 1973).

A origem da contagem dos tempos também tem sido arbitrada pelas diferentes culturas, mostrando claramente que todas as datas são uma forma evidente de medida intervalar.

Cada cultura estabeleceu um padrão de contagem de tempo, relacionando-o com referenciais vinculados a momentos e efemérides de grande significado na sua existência. Assim, se tomarmos como referência o ano 2000 do calendário Gregoriano, adotado hoje em substituição ao Juliano, ele corresponderia ao ano 2753, segundo o calendário romano; 2749 , consoante ao dos babilônios; 6236 de acordo com o primeiro dos egípcios; 5760 no calendário judaico; 1420 naquele muçulmano; 2544, segundo os budistas; 5119 no calendário maia e 208 de acordo com o calendário da Revolução Francesa. (DUCAN, 1998).

O mais importante a ser considerado é que, embora os calendários e os relógios sejam constantes, o tempo é relativo, parecendo que passa depressa em certas situações e demora em outras. Minutos numa cadeira de dentista parecem horas; horas ao lado de quem amamos parecem minutos. Assim, percebemos o transcorrer de nossa vida segundo um tempo psicológico. E, portanto, o tempo não pode ser visto como uma dimensão única e independente do nosso viver, do nosso ambiente, como os 
mapas querem nos fazer acreditar. (MUEHRCKE, 1983).

Para a cartografia interessa como os aspectos espaciais mudam com o tempo. As mudanças se dão de duas maneiras. Os estados dos espaços podem mudar: o solo sofre erosão, os lagos se congelam e os seres vivos nascem, crescem e morrem. Em segundo lugar, a posição espacial pode se alterar com o tempo. Ainda, certas coisas se movem por si, outras, são acionadas por forças externas. O resultado da difusão de objetos, idéias, técnicas, informações no espaço está na mudança contínua da configuração deste. As mudanças tanto no estado como na posição possuem dois componentes: a velocidade da mudança e a forma como essa mudança se dá no tempo.

Com o fim de manter mapas ao corrente, seus elaboradores sempre deram preferência à cartografia de fenômenos com mudanças lentas, considerando temas de feições físicas e inorgânicas, deixando de lado temas que abordam processos de mudanças rápidas, como alterações geológicas e atmosféricas catastróficas, bem como processos cujo motor é o dinamismo da sociedade.

A forma como a mudança se dá no tempo pode ser avaliada através das tendências cíclicas e não cíclicas. Os fenômenos com mudanças cíclicas são aqueles que se caracterizam pelo retorno periódico à situação inicial, como a temperatura e a precipitação. Muitas vezes este comportamento fica mascarado quando são usadas as médias do período que, por sua vez, podem ainda variar conforme a definição do intervalo de tempo considerado.

Os fenômenos com mudanças não cíclicas apresentam flutuações com ritmos distintos em intervalos de tempo diferentes. (MUERHRCKE, 1983).

Tempo e espaço são vistos também como duas dimensões de uma mesma realidade, estando uma em conexão com a outra, manifestando permanente interdependência e interação, dependendo outrossim de todo o conjunto da materialidade do mundo que nos cerca. Não há, assim, espaço sem tempo nem tempo sem espaço. São manifestações da matéria em movimento.
(GOMES, 1991).

No incessante suceder-se do tempo, desde o infinito passado, indo para o eterno futuro nada se repete. Se o tempo é visto como uma progressão linear e irreversível o mesmo instante não se repete e o mesmo lugar já não será mais o mesmo. Tudo muda. Onde há mudança, há movimento.

O tempo com o conceito de linear e, ao mesmo tempo, de direcional passou a fazer parte da sociedade somente no século XVIII, a partir do que os seguidores de Newton postularam como trajetória natural de toda matéria em movimento: a linha reta.

Esta nova postura substitui o sentido de tempo essencialmente cíclico do homem medieval. Assim, a diferença de tempo tornou-se importante, pois podia ser convertida em distância.

Tempo e espaço definem posições e ocasiões de ocorrências singulares; a narração as conecta. Portanto, para TUAN (1974), o tempo importa mais que o instantâneo, pois as pessoas interessam-se mais pelas narrações do que pelas imagens estáticas. Assim, a linguagem verbal seria melhor para as crônicas do que a linguagem visual.

O que podemos apreciar à nossa frente no presente é a atualidade em sua dimensão espaçotemporal. Não podemos negligenciar que por trás dessa realidade há uma dinâmica social que produz o espaço, o espaço geográfico, do qual somos parte integrante. Este se relaciona com a história da humanidade. Nessa dinâmica, as sociedades foram se modificando, elaborando novas formas de sobrevivência, construindo novos espaços, sempre em resposta às demandas das suas necessidades. (SANTOS, 1982).

No presente momento da história humana, o tempo ganha indiscutível importância e significado. E o espaço expressa os tempos, caracterizando o tempo de determinada relação social. Pois, é no espaço produzido que se opera a materialização de tempo mediante o trabalho dos homens. (RIBEIRO, 1988).

O tempo presente como real no espaço, agora, expõe momentos que já se foram, expressos como objetos geográficos, tidos como 
formas do presente, podendo abrigar uma essência, participando da vida atual.

Para que o presente possa ser apreendido devemos avaliar o passado no que pode conter as raízes do presente no seu desenrolar histórico mediante o suceder e a transição dos momentos dos modos de produção. (SANTOS, 1982).

A dimensão tempo em geografia pode ser apreendida, de acordo com SANTOS (1994), segundo duas óticas: o tempo como sucessão e o tempo como simultaneidade. O primeiro, é o tempo do suceder de acontecimentos. Há uma ordem temporal: um fenômeno vem depois de outro constituindo o tempo histórico, mais abstrato. O segundo, é o tempo dos fenômenos concomitantes, é o tempo que condiz mais com a vida em sociedade, coordenando espaços com um uso diferenciado de tempo entre os homens, portanto, um tempo mais concreto: cada ação se dá em seu tempo, mas as diversas ações se dão conjuntamente, numa seqüência diacrônica.

Assim, é o fato do existir homens usando sempre o tempo e o espaço que faz com que o espaço possa reunir variadas maneiras de uso relacionadas com possibilidades diferentes de uso do tempo.

Esta postura metodológica é básica para que a cartografia daqui para frente possa tentar construir representações dinâmicas condizentes com o entendimento da realidade como interação. Nesta, poderíamos vislumbrar o espaço constituído de fixos (casas, fábricas, plantações) e fluxos. Os fixos emitem ou recebem fluxos comandados pelas relações sociais. Os fluxos não têm a mesma velocidade e, neles, os elementos que se deslocam podem ser materiais (produtos, mercadorias, mensagens materializadas) e não materiais (idéias, ordens, mensagens não materializadas). Esse entendimento, portanto, vê a realidade como um conjunto de lugares onde o acontecer simultâneo dos diversos agentes considera o uso diferenciado do tempo. (SANTOS, 1994).

Na cartografia dinâmica não se podem menosprezar a relação espaço-tempo e seu vínculo com os níveis de análise da realidade $e$, conseqüentemente, também, com a escala de seu mapeamento.

Os períodos curtos são medidos em minutos ou horas e os períodos longos, em dias, semanas, meses ou anos. Já os períodos muito longos precisam ser contados em décadas e até em séculos. Os tempos longos são aqueles das grandes transformações que ocorreram e ocorrem na Terra, como a formação das rochas, o aparecimento da vida e depois o surgimento do homem. É o tempo da natureza, o dito tempo geológico, que conta bilhões de anos. Entretanto, as transformações que se dão na sociedade humana acontecem mais rápidamente. Desde a invenção da escrita até a era da informática, que vivemos atualmente, passaramse séculos. É o tempo histórico.

Fica patente que, na representação cartográfica, há estreitas relações entre a extensão de determinado conjunto espacial, o tempo e o número e a natureza dos critérios que definem sua identidade.

Em qualquer lugar, todo objeto, todo fenômeno e toda combinação destes congrega uma certa herança do passado e conta com determinado potencial para se projetar no futuro. Assim, toda organização espacial se identifica num certo intervalo de tempo, durante o qual ela pode ser considerada como uma característica original marcante. Se este intervalo de tempo for curto, intervêm muitos fatores e de forma localizada para determinar sua identidade. Se for longo, implicarão os fatores mais duráveis e mais universais, e o conjunto espacial será mais simples, porém, vasto. Assim, a singularidade de determinado universo de abrangência espacial é relativa. Esta unidade diz respeito a certo espaço e a certo tempo de duração, evidentemente não completamente independentes. Tal unidade se reporta a certa escala espaçotemporal, podendo corresponder a uma escala de representação cartográfica que seria definida, não só em função da extensão da manifestação, mas também do tema a ser tratado, dos detalhes a serem atingidos e dos meios de aquisição dos dados empregados. (JOLY, 1976).

Infelizmente, como já apontamos anteriormente, a grande maioria dos mapas temáticos produzidos apresenta uma visão 
estática. É mais cômodo abordar temas que não mostram grande dinamismo, mostrando a realidade como se fosse estática e imutável.

Tradicionalmente, também consideramos mapas que representam temas relacionados com o tempo distintamente daqueles referentes ao espaço, concentrando-nos, evidentemente, nestes últimos. A prática mais comum para construirmos a idéia do dinamismo é a de confrontarmos várias edições de um mesmo tipo de mapa, numa seqüência temporal.

Entretanto, podemos contar com mapas que incorporam o tempo, seja no conteúdo temático, seja na simbologia empregada.

Mesmo assim, temos que nos lembrar de que um mapa sempre será uma representação ultrapassada quando chegar nas mãos do usuário, pois envolve um certo tempo em sua elaboração. $O$ tempo real da tecnologia computacional poderá diminuir esta demora.

Dentro de uma desejável postura metodológica da cartografia temática já bem sistematizada, podemos concordar com CUENIN (1972) quando coloca que o dinamismo dos fenômenos pode ser apreciado no tempo (se traduz pelas variações quantitativas ou pelas transformações dos estados de um fenômeno, que se sucedem no tempo para um mesmo lugar) e no espaço (o fenômeno se manifesta através de um movimento, deslocando certa quantidade de elementos através de certo percurso, dotado de certo sentido e direção, empregando para isso, evidentemente um certo tempo). Ao considerarmos o movimento em relação ao tempo entra em jogo a noção de velocidade, bem como a avaliação do tempo de duração para realizar certo percurso. Como vemos, é impossível dissociarmos o tempo do espaço.

Dentro desta concepção básica, a cartografia dinâmica seria relativamente simples. Ao considerarmos apenas a apreciação quantitativa poderíamos estabelecer dois enfoques fundamentais: as variações no tempo e os movimentos no espaço. As primeiras poderiam ser contabilizadas ou por valores absolutos, enaltecendo as diferenças algébricas, ou por valores relativos, explorando as taxas de variação.

Os movimentos no espaço, por sua vez, serão representados pela articulação de flechas, com larguras proporcionais às quantidades deslocadas, seguindo roteiros estipulados. Mobilizaremos, assim, a variável visual tamanho, em implantação linear.

Para uma abordagem didática sobre a questão das representações dinâmicas, preferimos ficar com a proposta de CUENIN (1972). Foi ela que lastreou a organização dos nossos trabalhos voltados ao ensino de cartografia temática. (MARTINELLI, 1991, 1998, 1999, 2003).

BERTIN (1973), por sua vez, tem uma visão diferente neste empreendimento metodológico. Parte da relação do tempo como componente do dado, com a mobilização das duas dimensões do plano. Como já falamos, sendo o tempo ordenado linearmente, quando um dado o considera, as correspondências no plano transcrevem uma evolução sobre um diagrama.

Já quando um dado introduz combinadamente o tempo e a ordem geográfica, isto é o espaço, as correspondências traduzem um movimento. Mas sabemos que as duas dimensões do plano se esgotaram ao representar o espaço, o que constitui o problema básico da representação do movimento em cartografia. Para o citado autor, existem três soluções possíveis:

1. construir uma série de mapas. Esta solução, entretanto, pode esbarrar nas limitações do processo da leitura quando a série é muito longa. Entretanto, será válida para empreender a animação.

2. Representar o rasto e o sentido de um móvel, o que dará idéia de movimento no plano. A animação também pode aplicar esta sugestão.

3. Explorar uma variável visual compatível com o tempo dividido em categorias ordenadas: o valor numa seqüência de níveis de uma ordem visual. Entretanto, o resultado visual não sugere o movimento no plano, mas permite se ter uma imagem de conjunto da classificação de lugares numa ordenação cronológica.

Já MUEHRCKE (1983) dá destaque 
especial aos mapas que consideram a dimensão temporal da existência humana. Seriam aqueles que incorporam o tempo, seja no conteúdo temático, seja na simbologia empregada. Com base nestas considerações, aponta vários tipos de representações relacionadas com o tempo e o espaço.

\section{As representações}

Lastreados na revisão da literatura sobre o assunto até os dias atuais, vislumbramos os seguintes tipos de representações para a cartografia dinâmica:

\section{Mapas com diagramas localizados}

Ao lado dos mapas com fluxos de MINARD empreendidos em 1845, desenvolveram-se mapas com diagramas localizados, os "cartogramas", privilegiados por CHEYSON em 1878. A grande euforia das representações gráficas estimuladas por este mesmo autor na série "Álbuns de estatística gráfica", junto ao Ministério de Obras e à Estatística da França, deu margem a uma grande inventividade para a expressão das evoluções explorando, para tanto, os mais variados tipos de diagramas localizados.

Esses mapas, às vezes chamados na literatura pela designação francesa de cronocartodiagramas, ainda são muito explorados, principalmente para elementos climáticos, através de climogramas ou gráficos ombro-térmicos localizados.

Embora os mapas com cronogramas localizados exijam uma leitura ao nível elementar, gráfico por gráfico, quando estes são vistos, no conjunto, detectados como silhuetas podem auxiliar a vista a vislumbrar a formação de agrupamentos espaciais, caracterizados por agrupamentos de atributos, mobilizando, assim, as operações mentais que demandam a síntese.

Estes mapas, ainda em pleno uso nos dias de hoje, mostram a persistência no apego às representações localizadas para fenômenos que têm manifestação zonal.

\section{Mapas das mudanças espaciais}

São mapas que mostram as evoluções e mudanças ocorridas num intervalo de tempo. Eles podem ser qualitativos - registram as partes acrescidas ou removidas num intervalo de tempo e quantitativos - representam a ordem de grandeza destas mudanças.

A representação das alterações espaciais havidas levando em conta apenas a dimensão qualitativa pode ser concebida, a título de exemplo, como um mapa da dinâmica dos espaços agrícolas de determinada região. É mapa do tipo diacrônico. Tal mapa poderia ser indicativo de tendências tais como: nas áreas de maiores perdas de espaço agrícola poderia estar ocorrendo uma especulação imobiliária ou reserva de valor. As áreas de maiores ganhos poderiam denotar certa orientação para uma especialização hortifrutigranjeira, com forte dose de acréscimo de tecnologia, e nas áreas de relativo equilíbrio seriam as próprias acomodações dos sistemas agrícolas as responsáveis pelas flutuações.

Na evolução de determinado ambiente podemos apreciar, na seqüência de mapas, por exemplo, uma re-colonização florestal, vista como uma sucessão secundária.

No espaço urbano pode-se colocar em evidência as novas áreas construídas, fazendo ressaltar, por exemplo, a clara transformação de um pequeno centro periférico em cidade dormitório.

Numa apreciação quantitativa, os mapas das mudanças não precisam representar apenas se a alteração foi pequena ou grande. Podem ir além, registrando o valor absoluto da magnitude da mudança. Estes últimos apresentam um grave inconveniente, dificultando a correta avaliação, ao não apresentarem a grandeza de base sobre a qual houve a variação. Um acréscimo de 100 indivíduos numa população de 500 pessoas tem um significado bem diferente daquele que se daria em base a um efetivo de 5.000.000 de habitantes. 


\section{Mapas das mudanças vistas através da sucessão de intervalos de tempo numa única representação}

Estes mapas mostram as alterações, em superposição, num único mapa.

Mudanças qualitativas podem ser registradas em cores diferentes para cada data sobre o mesmo mapa tomado como ponto de partida.

No entanto, esta forma tradicional de resolver esta cartografia cai numa grave incoerência. A noção de tempo não é seletiva, e sim ordenada. Portanto, sua transcrição deverá ser feita pela ordem visual, do claro para o escuro,o que construirá rapidamente a imagem de conjunto. Responderá, instantaneamente, à pergunta: "Para onde está se deslocando o fenômeno?".

Esta representação ordenada pode ser explorada para o mapeamento exaustivo da seqüência das fases de vários processos dinâmicos em curso. Cada um será expresso por uma ordem visual distinta.

Um bom exemplo deste tipo de cartografia é aquele idealizado para a dinâmica da vegetação, na qual pode-se mostrar a transformação da composição dos grupos vegetais em vários processos, seja na sucessão e regressão, seja na flutuação e na degeneração/regeneração.

A coleção de mapas combinada com os respectivos mapas exaustivos de cada período, por sua vez, pode ser bastante reveladora. Os ciclos de culturas podem evidenciar facilmente as mudanças. A interpretação tornar-se-ia mais rápida pelo simples fato da coleção de mapas mobilizar imagens binárias, de fácil memorização para a comparação.

Os movimentos relacionados com o tempo podem ser representados mediante o registro dos pontos alcançados em datas marcantes ao longo de um itinerário de interesse.

A superposição de mudanças no tempo pode constituir também uma forma eficaz de se avaliar a expansão ou contração de um fenômeno em movimento com manifestação zonal. A representação isarítmica, em linhas que unem os pontos alcançados pelo fenômeno numa mesma data num determinado território, quando estabelecida em intervalos iguais de tempo pode revelar se o fenômeno está em processo de expansão ou retração.

A representação isarítmica do tempo pode ser reveladora mediante os mapas denominados de isocrônicos. Ao tratarmos de movimentos, como já apontamos, muitas vezes interessa mais saber o tempo gasto para cumprir determinado percurso. Podemos, então, mapear o tempo empregado pelos trabalhadores da periferia em seus deslocamentos diários para atingirem determinado centro industrial ou comercial. Conhecidos os caminhos a serem percorridos pelo meio de transporte coletivo dominante, ônibus, metrô ou trem de subúrbio, por exemplo, e os pontos atingidos em intervalos iguais de tempo, traçam-se as isócronas.

Esses mapas permitem o estudo das possibilidades de deslocamentos para trabalhadores das cidades onde moram. Pesquisas prospectivas neste sentido podem planejar a implantação de novas áreas para a construção de conjuntos habitacionais, bem como a instalação de um adequado sistema de transportes públicos.

A representação por isócronas coloca também em evidência a acessibilidade, isto é, o grau de relativa facilidade em que certo lugar pode ser alcançado. Os vários níveis de acessibilidade repercutem claramente na intensidade de fluxos entre vários lugares. (SILVA, 1982).

\section{Mapas das variações}

Nestes mapas o tempo está embutido na própria simbologia quantitativa. Mostram aumentos, estabilidade ou decréscimos num período mediante taxas de variação 
representadas pelo método coroplético, explorando duas ordens visuais opostas: cores frias e cores quentes.

Já salientamos em MARTINELLI (1991), baseados em MULLER (1984), que na solução coroplética a superfície da ocorrência passa a fazer parte do signo. A proposta melhorativa é a que recomenda colocar valores visuais correspondentes às taxas de variação dentro de círculos proporcionais aos denominadores. Para o presente caso o círculo proporcional a um valor absoluto tomado por base evitaria qualquer distorção no entendimento do fenômeno.

\section{Anamorfoses temporais}

Nesta categoria de mapas a dimensão temporal é incorporada diretamente à sua geometria de base. O tempo é substituído pela distância física. A escala do mapa estará em unidades de tempo. Tais representações tornam-se verdadeiros mapas topológicos, perdendo, assim, a propriedade básica do mapa cartográfico. (COLE e KING, 1968) (BERTIN, 1973).

Podemos considerar duas variantes nestas anamorfoses: aquelas em que a escala em unidades temporais é uniforme em todas as direções e aquelas em que, ao contrário, esta uniformidade não existe. Estes últimos são mais condizentes com a realidade, destacando variadas situações ou fatores que estariam interferindo na aludida uniformidade.

\section{Mapas de fluxos}

Os mapas de fluxos adquirem uma importância particular. Eles constituem, ao nosso ver, um capítulo à parte na cartografia dinâmica, merecendo grande destaque. Se por um lado constituem a única forma de representação quantitativa com manifestação linear, por outro compõem a representação dinâmica do movimento.

A cartografia dos fluxos, de certa forma, pode ser considerada como uma herança das primeiras incursões no mundo dos protótipos dos mapas temáticos realizados nos séculos XVII e XVIII, mediante as representações das redes de comunicação. Elas expunham uma classificação da viabilidade. Entretanto, a representação específica dos movimentos foi desenvolvida a partir das idéias plantadas, para o registro do avanço das tropas, seguindo um esquema fundamentado na noção do rasto e do sentido de um móvel.

Esta cartografia, como já apontamos, floresceu a partir do desenvolvimento dos transportes e do crescimento dos intercâmbios comerciais advindos da revolução industrial. Ela não pode ficar alheia à determinação da infra-estrutura utilizada. Constitui-se, assim, uma rede, que é percorrida, então, pelos fluxos, os quais acontecem como decorrência das diferenças de "potenciais" entre lugares interligados. (RIMBERT, 1990.)

A representação está lastreada, como já apontamos, na possibilidade gráfica do plano bidimensional em sugerir um movimento. Isto pode ser feito mediante o registro do rasto deixado por um móvel, que pode ser um ponto, uma linha ou uma área. Entretanto, só o ponto fornece um móvel capaz de sugerir um movimento que se manifesta linearmente, tornando-se uma flecha quando ele tem um sentido. Esta lucubração é denominada de "Método dos Fluxos". (BERTIN, 1973).

Quando os dados dos fluxos são integrados, isto é, computados nos dois sentidos, as flechas tornam-se faixas sem ponta, podendo contar com um acabamento retangular nas extremidades tangentes aos nós da rede de ligações.

Pelo fato de mobilizar a variável visual tamanho, o mapa dos fluxos oferece resposta visual fácil aos dois níveis de questões a ele colocadas. Em nível elementar: "Qual a intensidade do fluxo em tal trecho?" Em nível de conjunto: "Onde estão os maiores fluxos?" "Como se agrupam?" "Como se articulam no espaço?"

Com isto podemos identificar se há formação de pólos e controlar como se estrutura a rede de interligações e relacionamentos; se há um único sistema ou vários independentes, separados por possíveis barreiras físicas, políticas, econômicas, ideológicas de diferentes graus de permeabilidade. Pode-se verificar, também, se aparecem eixos 
preferenciais e se estes se definem mediante fluxos de maior intensidade. (CLAVAL e WIEBER, 1969).

Estes mapas podem, também, dar a idéia do relacionamento entre pares de terminais de fluxos, que podem ser cidades, colocando-as na categoria de dominantes quando seus maiores fluxos dirigem-se a cidades menores; e de subordinadas, quando seus fluxos mais intensos demandam a cidades maiores. No conjunto das cidades de um território é possível detectar sua organização regional. (ROCHA, 1974).

Dentro ainda do campo da exploração analítica, os mapas de fluxos podem indicar a interação, isto é, o grau de maior ou menor relacionamento entre lugares, o qual está estreitamente vinculado aos níveis de acessibilidade, como já vimos. (SILVA, 1982).

\section{Mapas animados}

A animação dos mapas não é nenhuma novidade. Já no início do século XX se almejava restabelecer a continuidade da série de mapas por intervalo de tempo através da animação cinematográfica. Eles evoluiriam no tempo, segundo determinada cadência. Tiveram muito sucesso, porém sua exploração não era econômica para a época. (LIBAULT, 1960).

Na década de 1960, do mesmo século, TOBLER(1970) já experimentava a animação por computador para simular a expansão urbana da região de Detroit.

Animação é qualquer apresentação em movimento, seja por filme, vídeo, computador. Mostra mudanças com variação de tempo, espaço e/ou atributo. Vai além da clássica apresentação em série de imagens seqüenciadas, como a de um carrossel de slides. Hoje, a seqüência é obtida por uma série muito grande de registros, cada passo assinalado por diminutas alterações. Pode incluir som: narração, música, efeitos sonoros. Esta seria a animação em multimídia. Pode, ainda, ser incluída numa apresentação em hipermídia.

Figura 1

\begin{tabular}{|c|c|c|c|c|c|c|}
\hline \multirow{3}{*}{$\begin{array}{l}\text { MÉTODO DE } \\
\text { ANIMACÃU } \\
\\
\text { por séries } \\
\text { temporais }\end{array}$} & \multicolumn{6}{|c|}{ CARACTERÍSTICAS } \\
\hline & \multicolumn{2}{|c|}{$\begin{array}{c}\text { Tempo } \\
\text { dinämica/estática }\end{array}$} & \multicolumn{2}{|c|}{$\begin{array}{c}\text { Variável } \\
\text { dinämica/estática }\end{array}$} & \multicolumn{2}{|c|}{$\begin{array}{c}\text { Espaøo } \\
\text { dinämica/estática }\end{array}$} \\
\hline & $x$ & 0 & 0 & $x$ & 0 & $x$ \\
\hline em área & 0 & $x$ & 0 & $x$ & $x$ & 0 \\
\hline $\begin{array}{l}\text { animaç̃o } \\
\text { temática }\end{array}$ & $x$ & 0 & $x$ & 0 & 0 & $x$ \\
\hline de processo & $x$ & 0 & $x$ & 0 & $x$ & 0 \\
\hline
\end{tabular}


A animação pode não ficar apenas na apresentação, pode ir muito além, ao ser interativa. $\mathrm{Na}$ simples apresentação, o observador não tem controle sobre o andamento: a animação apenas pode ser vista. Ao contrário, na animação interativa, o usuário passa a ter amplo domínio sobre seu curso. Ele pode intervir, girando em torno, se aproximando, se afastando da cena, bem como, rotacionando-a. Pode, também, dialogando com o computador, acrescentar-lhe novos dados ou colocar-lhe questões em busca de respostas.

LOBBEN(2003), de uma forma clara e didática, considera quatro categorias de animação: Animação por séries temporais, Animação em área, Animação temática e Animação de processo. As animações se dispõem num quadro de dupla entrada, conforme as características, - tempo, variável e espaço - e da consideração destas em estado estático ou dinâmico.

\section{Animação por Séries Temporais}

Esta animação é indicada para apreciar mudanças de determinada manifestação, ocorridas ao longo do tempo. O tempo flui, a variável permanece a mesma e o mapa-base da representação mantém-se inalterável. A variável, que é a ocorrência, ao longo do tempo, aparece ou desaparece, amplia ou reduz a extensão de sua manifestação. Com um mesmo mapa-base são criadas múltiplas representações, as das ocorrências de cada etapa da série, podendo seguir o ritmo: dia, semana, mês, ano, etc.

\section{Animação das Áreas}

Nesta animação varia a posição do ponto de vista do observador que vislumbra a representação, que permanece fixa. Assim, o usuário pode visualizar a área de vários ângulos, mudando, a toda hora, o sentido e a direção de seu movimento, seja em vôos rasantes ou em determinada altura, podendo, ainda, intervir na respectiva velocidade do vôo.

Um exemplo desta aplicação está nos mapas rodoviários ou plantas de cidades interativas, disponíveis na internet, para a procura de um endereço desejado.

Esta animação encontra largo emprego na visualização de paisagens. O observador pode, também, apreciar a variabilidade de certas manifestações, sejam qualitativas como quantitativas, de um lugar para outro, conforme vai se deslocando. Num modelo digital do terreno podem-se programar visualizações a partir de pontos de vista que vão variando conforme a necessidade do observador.

\section{Animação Temática}

$\mathrm{Na}$ animação temática as localizações permanecem constantes, enquanto o tempo e as variáveis se alteram, estas últimas, em seus atributos ou valores. Nesta animação a ênfase é dada à variável, que muda com o tempo.

Certos métodos de representação da cartografia temática para mapas estáticos podem ser explorados para criar mapas temáticos animados. Enquadram-se, neste caso, as seqüências temporais de mapas coropléticos e de mapas com figuras geométricas proporcionais. A magnitude das variações pode ser apreciada no fluir da animação.

Como aplicações das animações temáticas, podemos citar aquelas que se dedicam a revelar o comportamento das mudanças das variáveis ao longo do tempo para um mesmo lugar.

\section{Animação de Processo}

A animação de processo ressalta, ao mesmo tempo, dois atributos importantes: o movimento e a trajetória. Permite ao usuário apreciar a contínua evolução de um processo (EPSTEIN,1990). Por exemplo, diante de um desastre de derramamento de petróleo no mar pode-se apreciar o fluxo contínuo da mancha, a 
alteração da velocidade de seu deslocamento, bem como a modificação de sua forma. Exibe todo o processo em curso.

A aplicação desta animação, embora de construção complicada, está na possibilidade de modelização de processos.

\section{A cartografia dinâmica de síntese}

Em geral, a cartografia de síntese é pensada junto a situações estáticas. Mas podemos elaborá-la, também, para abordagens dinâmicas. Pode-se considerar o exemplo que leva ao estabelecimento de tipos de evolução populacional.

Para se chegar a esta síntese é necessário fazer um tratamento dos dados. Ele poderá ser elaborado a partir da coleção de gráficos evolutivos.

Todos os gráficos evolutivos construídos ao nível analítico em papel mono-log para as diferentes unidades observacionais serão classificados visualmente, aproximando aqueles que mais se assemelham, procurando formar grupos com características similares de evolução. Cada grupo constituirá um "tipo" que será qualificado na legenda por epítetos específicos e concisos como:

- evolução muito positiva;

- evolução positiva;

- evolução ligeiramente positiva;

- evolução ligeiramente negativa ou nula;

- evolução negativa;

- evolução fortemente negativa. (PITTE, 1991)

Cada rubrica da legenda, assim especificada, poderá receber uma cor indicadora para ser lançada no mapa que expressará a síntese. Podemos considerar que os "tipos" detêm características distintas. A transcrição adotará a seletividade. Se, ao contrário, entrevermos que os "tipos" possam constituir duas ordens opostas - os que têm crescimentos se opondo aos que incluem decréscimos - fica evidente que a legenda deverá ser organizada com duas ordens visuais opostas: das cores quentes, desde as mais escuras até as mais claras, passando, depois, para as cores frias, desde as mais claras até as mais escuras.

RIMBERT (1968) inclui, também, como raciocínio de síntese, a dupla comparabilidade reduzida a uma simples diferença: um balanço, mostrando os saldos positivos ou negativos em vários níveis de valores absolutos. É claro que - mapa não exibirá mais os dados, mas sim a informação. As categorias destes saldos formariam a tipologia.

\section{Considerações Finais}

Em plena revolução tecnológica operada de forma mais incisiva na passagem do final do século XX para o início do século XXI, já podemos vislumbrar certas orientações para uma consolidação de uma cartografia dinâmica mais consistente. A própria concepção de cartografia, hoje, tem incorporado o conceito de visualização científica, já aplicado com sucesso em outras áreas do conhecimento. A visualização cartográfica tornou-se conceito central para a moderna cartografia - a geomática. Não equivale à cartografia, porém afeta seus três aspectos fundamentais: novas técnicas de produção cartográfica, comunicação e cognição. Visualização tem a ver com o conteúdo, portanto, deverá ser considerada no contexto sócio-cultural no qual a informação cartográfica será empregada.

Sem dúvida alguma, todos estes avanços inovadores possibilitarão à geomática grande agilidade e barateamento na obtenção de produtos cartográficos. Mas, mais importantes são os acréscimos qualitativos, permitindo interações com incontestável incremento na compreensão de ampla gama de assuntos. Disto emerge uma cartografia dinâmica, na qual a manipulação interativa dos dados espaciais promoverá consistente mudança na cartografia nos tempos atuais. 
Assim, ao incorporarmos o tempo na representação dos fenômenos, podemos dispor nos dias de hoje, graças aos avanços da geomática, principalmente em ambiente multimídia, de dois novos e essenciais modos de expressão: a interação e a animação. A interação requer um tempo para que o analista planeje uma mudança desejada na representação. A animação, por seu turno, exige um tempo para expressar mudanças de posições e/ou de atributos dos elementos gráficos, numa seqüência de exposições. (DI BIASE et al., 1994) (LOBBEN, 2003).

A multimídia interativa tem a vantagem de integrar imagem, texto, som e movimento, com grande potencial de aplicação na educação, na pesquisa e no entretenimento. Para a apresentação da informação espaço-temporal, a multimídia tem, hoje, como poderoso aliado, o uso da animação. A animação acústica também pode vir complementarmente.

As aplicações da multimídia podem ser implementadas empregando a hipermídia. Ela inclui a navegação em material armazenado em várias mídias: texto, grafismos, efeitos sonoros, música, vídeo.

A possibilidade de uma cartografia virtual, por sua vez, se insere no domínio da realidade virtual. Ela estaria no contexto dos sistemas computadorizados dotados de ampla série de aplicações tridimensionais e de multimídia, que passaria a ter a habilidade de combinar, com grande impacto sobre os sentidos dos usuários, uma interação entre a experiência com o mundo real e o material gerado por computador. (ARTIMO, 1994).

\section{Bibliografia}

Antunes, A. R. et al., 1993, Estudos Sociais. Teoria e prática. ACCESS Editora, Rio de Janeiro.

Artimo, K. "The bridge between cartographic and geographic information systems". In: Mac. Eachren, A. M. e Taylor, D. R. F. (ed.), 1994, Visualization in modern cartography. Elsevier, Oxford.

Bertin, J., 1973, Sémiologie graphique: les diagrammes, les réseaux, les cartes. Mouton, Gauthier - Villars, Paris.

Claval, P. e Wieber, J-C., 1969, La cartographie thématique comme méthode de recherche. Les Belles Lettres, Paris.

Cole, J. P. e King, C. A. M, 1968, Quantitative geography. Techniques and theories in geography. John Wiley and Sons Ltd, London.

Cuenin, R., 1972, Cartographie générale (tome 1), Eyrolles, Paris,

Deus, J.B., 1995,"Um breve comentário sobre o espaço e o tempo em geografia. Boletim Goiano de Geografia, 115(1): 109-116.
DiBiase, D. et al., 1994, “Multivariate display of geographic data: applications in earth system science". In: Mac. Eachren, A. M. e Taylor, D. R. F. (ed.), 1994, Visualization in modern cartography. Elsevier, Oxford.

Ducan, D. E., 1998, The calendar. London.

Epstein, M., 1990, "Animation in the classroom: a low cost, educationally effective approach". T.H.E. J ournal: 54-58.

Gomes, H., 1991, Reflexões sobre teoria e crítica em Geografia. CEGRAF/UFG, Goiânia.

Joly, F., 1976, La cartographie. PUF, Paris, Libault, A., 1960, Histoire de la cartographie. Chaix, Paris.

Libault, A., 1975, Geocartografia. Nacional/USP, São Paulo.

Lobben, A., 2003, “Classification and application of cartographic animation". The Professional Geographer, 55(3): 318-328.

Mac. Eachren, A. M. e Taylor, D. R. F. (ed.), 1994, 
Visualization in modern cartography. Elsevier, Oxford.

Martinelli, M. 2003, Cartografia temática: caderno de mapas. EDUSP, São Paulo.

Martinelli, M., 1991, Curso de cartografia temática. Contexto, São Paulo.

Martinelli, M., 1998, Mapas e gráficos: construaos você mesmo. Editora Moderna, São Paulo

Martinelli, M., 1999, As representações gráficas da geografia: os mapas temáticos. Edição do Autor (tese de livre-docência), São Paulo.

Martinelli, M., 2003, Os mapas da geografia e cartografia temática. Contexto, São Paulo,

Mc. Harg, I. L., 1969, Design with nature. The Falcon Press, Philadelphia.

Muehrcke, Ph. C., 1983, Map use: reading, analysis and interpretation. Madison, J. P. Publications, Nova York.

Muller, J-C., 1984, "Ignorance graphique ou cartographie de l'ignorance?" Cartographica, 20 (3): 17-30.

Pitte, J.R., 1991, Géographie terminales. Nathan, Paris.
Ribeiro, W. C., 1988, "Relação espaço/tempo: considerações sobre a materialidade e dinâmica da história humana". Terra Livre, (4): 39-54.

Rimbert, S. 1968, Leçons de cartographie thématique. Sedes, Paris.

Rimbert, S., 1990, Carto-graphies, Hermes, Paris.

Rocha, R. U. M., 1974, "Subsídios à regionalização e classificação funcional das cidades: estudo de caso - Estado de São Paulo". Revista Brasileira de Geografia, 36 (3): 30-74.

Santos, M., 1982, Pensando o espaço do homem. Hucitec, São Paulo.

Santos, M., 1994, Técnica, Espaço, Tempo. Globalização e meio técnico - científico informacional. Hucitec, São Paulo.

Silva, B. C. N., 1982, "Previsão através de mapas de probabilidades - o caso das precipitações anuais no Estado da Bahia". Geografia, 7(1314): 101-109.

Steinberg, J. e Usser, J.,1988, Cartographie dynamique applicable à l'aménagement. Sedes, Paris.

Tuan, Y., 1974. Topophilia: a study of environmental perception, attitudes, and values. Prentice - Hall Inc. Englewood Cliffs, New Jersey.

Trabalho enviado em junho de 2005

Trabalho aceito em julho de 2005 
